\title{
O COMENTÁRIO ENSAÍSTICO COMO TRADUÇÃO: O EXEMPLO DE MON COEUR MIS À NU, DE CHARLES BAUDELAIRE
}

\author{
Thiago Mattos de Oliveira \\ Universidade de São Paulo, São Paulo, São Paulo, Brasil
}

Resumo: Ao traduzir o projeto póstumo Mon cœur mis à $n u$, de Charles Baudelaire, a partir dos seus muitos inacabamentos, propus um espaço de reescrita em que três traduções possíveis operam simultaneamente, cada qual colocando em cena uma dimensão específica dos seus inacabamentos: marcas matéricas do manuscrito; inexistência de uma ordenação definitiva; rede de historicidades das edições e traduções anteriores. Neste ensaio, ocupo-me especificamente do caso da (não) ordenação de Mon cœeur mis à $n u$, procurando mostrar como a estratégia do comentário-ensaio como tradução me permitiu estabelecer uma relação com Mon cœur mis à $n u$ que nem recorre a soluções apressadas (ordenação randômica digital, edição em folhas avulsas etc.) nem se limita a uma inviável restituição linear e cronológica dos manuscritos. Ao percorrer o texto ensaisticamente, num tipo específico de comentário que Antoine Berman chegou a esboçar teoricamente no seu também inacabado L'âge de la traduction, produz-se uma tradução possível desse texto, desenhada a partir de linhas de força que, atravessando a leitura e a escrita ensaística, talham, estilhaçam e rearranjam o original. Para diferenciar o comentário ensaístico de tradução da nota de tradutor, também é brevemente exposto o trabalho de Ana Cristina César sobre o conto Bliss, de Katherine Mansfield.

Palavras-chave: Comentário de tradução; Nota de tradução; Mon cœur mis à $n u$; Charles Baudelaire; Ensaio. 


\title{
ESSAYISTIC COMMENTARY AS TRANSLATION: THE EXAMPLE OF MON COEUR MIS À NU, BY CHARLES BAUDELAIRE
}

\begin{abstract}
When translating Charles Baudelaire's posthumous Mon cœur mis à $n u$ stemmed from its many unfinishments, I offered a rewriting space in which three possible translations run simultaneously, each one of them presenting a specific dimension of its unfinishments: material marks of the manuscript; the inexistence of a defined ordering; a grid of historicities of earlier editions and translations. In this essay, I undertake specifically the case of Mon cœur mis à nu's (non) ordering, seeking to reveal how the strategy of preparing a commentary-essay understood as a translation allowed me to establish a relation to Mon cœur mis à $n u$ that neither appeals to rushed solutions (random digital ordering, loose leafs edition etc.) nor limits itself to an impractical linear chronological restoration of the manuscripts. In traversing the text in an essayistic way, in a specific form of commentary that Antoine Berman came to outline theoretically in its also unfinished $L$ 'âge de la traduction, a possible translation of this text is produced, drawn from lines of force that, crossing essayistic reading and writing, carves, shatters and rearranges the original. In order to discriminate essayistic commentary of translation from translator's note, Ana Cristina Cesar's work on Katherine Mansfield's tale Bliss is also briefly handled.
\end{abstract}

Keywords: Commentary of translation; Translatorss note; Mon cœur mis à $n u$; Charles Baudelaire; Essay.

A tradução é por natureza imperfeita - inacabada. É por isso que sua figura é o espectro, destituído de corpo. Mas esse defeito é seu mérito: a tradução torna a obra múltipla ${ }^{1}$. Anne-Laure Rigeade

1.

Quando propus (re)traduzir Mon cœur mis à nu, de Charles Baudelaire, levando em consideração seus muitos tipos de inaca-

1 “La traduction est par nature imparfaite - inachevée. C'est pourquoi sa figure est le spectre, qui manque de corps. Mais ce défaut est son gain: la traduction rend l'œuvre multiple." (2007, p. 11, tradução minha)

Cad. Trad., Florianópolis, v. 38, $\mathbf{n}^{0}$ esp. Baudelaire 150 anos, p. 135-156, ago-dez, 2018 
bamento ${ }^{2}$ - da montagem do manuscrito como livro ao estatuto das "notas", "planos" e "aforismos" que o compõem -, vi-me diante de um impasse: como chegar a uma reescrita que abrangesse de uma só vez os inacabamentos que eu então identificava? Isto é, como construir uma reescrita que, ao mesmo tempo: a) trouxesse a realidade matérica do manuscrito (rasuras, acréscimos, quebras de linha, ambiguidade entre maiúsculas e minúsculas etc.); b) colocasse em questão a ordenação prévia das "notas" baudelairianas c) disponibilizasse um espaço reservado para meus comentários críticos; d) e fosse, ainda assim, legível, ou, na pior das hipóteses, ao menos realizável?

Uma solução possível, ainda que perigosamente próxima de um "simulacro" de "inacabamento absoluto", "desordenação total", seria desfazer a ordenação canônica de Malassis, pedir para um designer reproduzir a caligrafia de Baudelaire na tradução (algo por si só problemático, seja na sua viabilidade prática, seja no que tem de obsessivamente menardiano), reunir esses papeis avulsos

${ }^{2}$ Pesquisa de doutorado intitulada $O$ rascunho contínuo: duas retraduções de Mon coeur mis à nu, de Charles Baudelaire, realizada no Programa de Estudos Linguísticos, Literários e Tradutológicos em Francês (USP) com apoio da Fapesp (2015/14677-8) e sob a orientação do Prof. Álvaro Faleiros.

${ }^{3}$ Publicado postumamente por Eugène Crépet como parte das Euvres posthumes (editora Quantin) de Baudelaire, em 1887, Mon cœur mis à nu é um conjunto de notas, aforismos, esboços de capítulo, lembretes pessoais etc. para uma obra por vir. Não se trata, como assim intitulou a edição de E. Crépet, de um "journal intime", mas de uma obra (projeto de obra) atravessada por múltiplos inacabamentos, indecisões e encruzilhadas. Ao publicar Mon cœur mis à nu, é preciso fazer escolhas que dizem respeito à própria construção do livro. Poulet-Malassis, editor das Fleurs du mal, recebe os manuscritos de Mon cour mis à nu de Charles Asselineau, que os recebera, por sua vez, de Madame Aupick, mãe do poeta. As notas relativas a Mon cœur mis à $n u$ eram um conjunto de papeis avulsos, identificados somente com o cabeçalho "Mon cœur mis à nu". Malassis, então, sequencia as notas - a edição de Georges Blin e Jacques Crépet (1949), além das edições de Claude Pichois (1983 e 2001), destacam que se trata de uma ordenação arbitrária: não se sabe que critérios foram adotados; já Tomaz Tadeu (2009), terceiro tradutor brasileiro de Mon cœur mis à $n u$, acredita que Malassis pode ter obedecido à ordenação do manuscrito tal qual o recebeu, seguindo uma ordenação prévia construída sabe-se lá por quem ou por que motivações.

Cad. Trad., Florianópolis, v. 38, $\mathrm{n}^{0}$ esp. Baudelaire 150 anos, p. 135-156, ago-dez, 2018 
numa caixa e assim dar por encerrada a tradução de Mon cœur mis à $n u$ "a partir dos seus inacabamentos". Outra solução, não menos apressada, seria se deixar encantar de imediato pelos discursos sobre as rupturas e inovações de leitura e escrita permitidas pelo hipertexto ${ }^{4}$, produzindo uma tradução de ordenação randômica hipersaturada de imagens, links para outros sites, informações enciclopédicas, variações, toda uma suposta dispersão radical que talvez nem seja tão radical nem seja minimamente legível ${ }^{5}$. Em ambos os casos, está em jogo um tipo de relação com a reescrita de Mon cœur mis à nu que leva a um desejo de "se livrar do problema", entregando para o leitor retextualizações no mínimo ilegíveis (para não dizer irrealizáveis), além de permeadas por certa convicção excessiva na possibilidade de um estado "plenamente inacabado", de uma "reescrita total", na qual ironicamente ecoa a mesma "escrita total" que atravessa o projeto literário de Baudelaire ${ }^{6}$.

Tornava-se claro que eu não poderia propor nem uma única reescrita "total" e "ideal" nem uma reescrita pretensamente "crua", sem as "impurezas" do gesto editor e tradutor - o texto no seu

\footnotetext{
${ }^{4}$ Komesu (2005), num artigo que é um balanço detalhado dos exageros teóricos e alcances reais do suporte digital, resume a dinâmica do recurso hipertextual em seis palavras-chave relativamente autoexplicativas: intertextualidade, não-linearidade, volatilidade, fragmentariedade, espacialidade topográfica e multissemiose.

5 Além do trabalho de Komesu (2005), também destaco um artigo de Possenti (2002) e um livro recente de Benhamou (2014) sobre os limites da dinâmica hipertextual.

${ }^{6}$ Mon cœur mis à nu retoma, na verdade, uma ideia de Edgar Allan Poe, My heart laid bare, livro que o poeta estadunidense imagina nas suas Marginalia e que seria um livro "total", o livro final, fiel ao seu título e, por isso mesmo, impossível de ser realizado: "Se um homem ambicioso quiser revolucionar, de uma só vez, o universo do pensamento humano, da opinião humana e do sentimento humano, a ocasião está dada, a estrada para o renome imortal se abre diante dele, reta e sem obstáculos. Tudo o que tem que fazer é escrever e publicar um pequeno livro. Deve ser simples, algumas palavras claras: 'Mon cœur mis à nu' [My heart laid bare]. Mas esse pequeno livro deve ser fiel a seu título. Escrevê-lo, eis a dificuldade. Nenhum homem poderia escrevê-lo, ainda que ousasse. O papel se contorceria e se consumiria ao menor contato com a pena em chamas" (POE, 1995, p. 1097, tradução minha).
}

Cad. Trad., Florianópolis, v. 38, $\mathrm{n}^{0}$ esp. Baudelaire 150 anos, p. 135-156, ago-dez, 2018 
estado intocado, primordial e ideal. Pelo contrário, era preciso fazer do espaço de reescrita de Mon cœur mis à nu um espaço plural (porque habitado por mais de uma reescrita possível) e singular (porque construído por um determinado sujeito tradutor segundo seus modos de dar a ver e a ler aquela obra, ou projeto de obra). Não se tratava de chegar a uma "mínima intervenção possível", como se a mera existência do arqueólogo arruinasse toda ruína, mas de construir modos singulares de reescrita, guiados pelos pontos nevrálgicos da minha leitura. Como afirma Jerónimo Pizarro, editor de algumas possibilidades de Livro do desassossego,

\begin{abstract}
[...] o editor não deve fazer emendas ou alterações em silêncio. Para mim a questão não é a quantidade (oferecer muita ou pouca informação), mas a transparência: quem trabalha um arquivo alheio e obras alheias (que às vezes o autor não sabia como organizar ou sequer havia pensado como 'obra'), deve declarar como se constituiu esse conjunto ('obras') e cada um dos elementos ('volumes') dos quais participou ativamente ${ }^{7}$ (PIZARRO apud GIMÉNEZ, 2013, p. 166, tradução minha).
\end{abstract}

Cheguei, portanto, a três propostas simultâneas de reescrita, cada uma construída sobre um Mon cœur mis à nu possível: 1) uma reescrita centrada na realidade matérica do manuscrito, propondo uma transcrição diplomática ${ }^{8}$ e sua respectiva tradução; 2) uma re-

7 “...lo que a mí me ha interesado es reiterar un principio fundamental de la crítica textual: el editor no debe hacer enmiendas o alteraciones en silencio. Para mí la cuestión no es de cantidad (ofrecer mucha o poca información) sino de transparencia: quien trabaja un archivo ajeno y contrafirma obras ajenas (que a veces el autor no sabía cómo organizar o ni siquiera había concebido como 'obras'), debe declarar cómo se fraguó ese conjunto ('obras') y cada uno de los elementos ('volúmenes') en los que activamente participó".

${ }^{8}$ Pichois (2001) tem uma edição diplomática de Mon cœur mis à nu. Contudo, não só há alguns problemas de transcrição (por ex.: quebras de linha da nota 21 e troca de "immoralité" por "immortalité" na nota 26), como a sua relação com o manuscrito também parece ser outra, de caráter mais documental e menos processual

Cad. Trad., Florianópolis, v. 38, $\mathrm{n}^{0}$ esp. Baudelaire 150 anos, p. 135-156, ago-dez, 2018 
escrita centrada na variabilidade de ordenações, propondo uma ordenação alternativa que nem recorre à suposta aleatoriedade absoluta nem à hipotética reconstrução de uma "artificial e linear linha cronológica” (GALÍNDEZ, 2009, p. 12); pelo contrário, recorre-se a uma reordenação a partir do trabalho de comentar o texto, seguindo as linhas de força que estruturam meu modo de entrar e percorrer Mon cœur mis à nu e, portanto, remontá-lo criticamente; 3) por fim, uma reescrita imaginada em suporte digital, utilizando-se do arquivo digital ${ }^{9}$ para explicitar as camadas de historicidades editoriais e tradutórias de Mon cœur mis à nu, promovendo o acesso às variações de edições e traduções franco-brasileiras.

Para este ensaio, limito-me a expor as estratégias construídas para colocar em tensão, a tal ponto que promova fissuras e estilhaços, a ordenação canônica de Malassis. Tentarei expor a relação entre comentário e tradução, ou melhor, o comentário como tradução, e em que medida pode ser uma estratégia tradutória que torna possível a remontagem do texto segundo outros lastros, outras linhas de força, abrindo caminho para deslocamentos na ideia de "método" tradutório.

2.

A relação entre comentário e tradução nos Estudos da Tradução é menos simples do que pode parecer. A tradução é um modo de comentar o original? Notas, prefácios e posfácios de tradutor são comentários da tradução? Quais são as fronteiras entre comentar a tradução e seu "original”? Comentar um texto é o mesmo que o traduzir? Etc.

9 Para mais detalhes sobre o arquivo digital, sugiro consultar os trabalhos do grupo Nenhum problema tem solução: um arquivo digital do Livro do Dessassossego, de Fernando Pessoa; uma boa síntese do projeto pode ser encontrada em Portela (2013).

Cad. Trad., Florianópolis, v. 38, $\mathbf{n}^{0}$ esp. Baudelaire 150 anos, p. 135-156, ago-dez, 2018 
Um prefácio de tradutor pode ser um comentário de tradução, mas não necessariamente ${ }^{10}$. Do mesmo modo, nem toda nota de tradutor é necessariamente um comentário de tradução. Um ensaio sobre um texto estrangeiro pode ser uma tradução - ou não. Há certos limites sísmicos que carecem de teorização específica.

Comecemos, portanto, a delimitar nosso terreno.

Toda tradução é um modo de comentar o texto. Nas palavras de Anne-Laure Rigeade (2007, p. 10, tradução minha), "como o comentário, a tradução atualiza a obra e promove assim a sua lenta elucidação" ${ }^{11}$. O comentário e a tradução são modos de interpretação. Mas o contrário (se o comentário do texto é um modo de traduzi-lo) precisa ser ainda especificado. Por ora, fiquemos com a seguinte definição geral: o comentário de tradução pode ser tanto a análise crítica geral de uma obra quanto a análise microscópica, o comentário linha a linha, não necessariamente no sentido de linearidade, mas no sentido da leitura da letra. Neste último caso, é possível dizer, acompanhando Antoine Berman (1999), que o comentário do texto se torna uma maneira de traduzi-lo. Voltaremos à questão mais tarde. Ainda me parece necessário tratar do estatuto específico da nota de tradutor, que, apesar das semelhanças, não se confunde com o comentário como tradução.

Para minhas questões, dois nomes me interessam especialmente: Ana Cristina Cesar (1999) e Antoine Berman (1999).

As notas produzidas por Ana Cristina Cesar para a sua tradução do conto Bliss, de Katherine Mansfield, ocupam um limite impreciso entre a nota de tradutor pura e simples e o comentário (produção de um texto ensaístico autônomo) do original. Por isso mesmo, ajuda a lançar luz sobre as diferenças e simetrias entre um e outro. Berman, por sua vez, constrói em L'âge de la traduction um tipo

10 Para não sairmos da constelação Mon cœur mis à nu, sugiro a consulta da minha dissertação de mestrado: (Re)traduções brasileiras de Mon cœur mis à nu, de Charles Baudelaire (MATTOS, 2015) e $A$ retradução de poetas franceses no Brasil: de Lamartine a Prévert (FALEIROS; MATTOS, 2017).

11 “comme le commentaire, la traduction actualise l'oeuvre et travaille ainsi à sa lente élucidation.”

Cad. Trad., Florianópolis, v. 38, $\mathrm{n}^{0}$ esp. Baudelaire 150 anos, p. 135-156, ago-dez, 2018 
de comentário do original que se torna uma tradução possível do próprio original, desenvolvendo em paralelo uma reflexão sobre o tipo de fazer tradutório, crítico e ensaístico que está em jogo: como e por que certos modos de comentar um texto podem se tornar traduções desse texto. Uma coisa parece ser a nota de tradução, inserida em rodapé ou fim de texto, remetendo aos mais variados tipos de informação: soluções de tradução, fatos históricos, exegese, etc. Outra é o comentário do texto, que o percorre criticamente e, assim, produz uma tradução possível.

A tradução de Ana Cristina Cesar é sua dissertação de mestrado (O conto Bliss anotado, ou "Paixão e técnica: tradução, em língua portuguesa, do conto Bliss, de Katherine Mansfield, seguida de 80 anotações”). Sua tradução-dissertação começa com uma introdução (seção I), em que pensa duplamente o lugar (no sentido de localização e no sentido de importância) das notas e expõe as linhas gerais que guiaram sua tradução. Segue a isso a seção II, nomeada "Tradução", ainda que não seja a tradução propriamente dita. Nela, Ana Cristina Cesar tenta entender por que suas notas se concentraram sobretudo nas páginas $1,2,6,11,14,18$ e 19 do texto traduzido, recorrendo a uma análise crítica dessas passagens, que são os pontos sísmicos do conto. Por fim, identifica e explica aspectos gerais do texto, como o "tom" e o ponto de vista narrativo. Começa, então, o conto em inglês, seguido da sua tradução. E, por fim, as 80 notas, que não ocupam o rodapé, mas a parte final do trabalho.

Aqui, as notas de pé de página, essencialmente discretas, são promovidas à categoria da própria substância do texto. Trata-se, na realidade, de uma dissertação formada por notas de pé de página, expressão essa que deixa de ter propriedade, uma vez que as notas ultrapassam o espaço reduzido de um pé de página e passam, efetivamente, a ocupar o lugar mais privilegiado. (CESAR, 1999, p. 285)

Cad. Trad., Florianópolis, v. 38, n $^{0}$ esp. Baudelaire 150 anos, p. 135-156, ago-dez, 2018 
As notas deixam de ser notas de rodapé e passam a ocupar um lugar próprio, um espaço conectado simultaneamente ao original e à sua tradução. Apesar de não deixarem de ser "notas de tradução", sua distribuição e seu tom têm certos ecos ensaísticos.

Pretendia escrever um ensaio geral sobre a tradução para o português do conto Bliss, de Katherine Mansfield, complementando-o com notas de pé de página, que abarcariam problemas específicos. Mas o processo se subverteu espontaneamente (ou se inverteu) e logo ficou evidente que as notas haviam absorvido toda a substância primordial do ensaio 'a respeito da tradução. Mais ainda: as oitenta notas acabaram ficando mais extensas do que a própria história ou sua tradução e foram desvendando gradualmente a forma como o processo de tradução se estava efetuando; elas convergem, passo a passo, para os movimentos da mão e da mente do tradutor (CESAR, 1999, p. 285-286).

Essas notas deixam de servir para "esclarecer" o texto, ainda que mantenham algum traço de explicação e desvendamento, e passam a expor os percursos e percalços do processo de leitura, escrita e tradução. Reparem, de todo modo, que continuam sendo notas a serviço da tradução, ou melhor, notas construídas a reboque do processo de tradução propriamente dita. Explicam acréscimos ("Um pequeno acréscimo foi feito, para marcar o ritmo de forma mais convincente", nota 79), construções sintáticas ("Aqui houve inversão na ordem, para se conseguir mais tensão sintática e mais ritmo", nota 66), construções metafóricas ("Mantive a metáfora relativa ao monóculo, mesmo que os leitores a considerem enigmática", nota 63) etc. E também expõem impasses: "Vivo procurando substantivos que possam expressar pronomes, como it, this e one. É possível que minha escolha imponha uma determinada interpretação do texto" (nota 18); "Nesta passagem há uma pequena dúvida: quem é que sempre demonstrava frieza? Face ou Miss Fulton?" (nota 57); "Estou usando excessivamente a palavra 
sublime, mas não consigo encontrar melhor tradução para blissful. Extático não serviria, porque soa exatamente da mesma forma que seu homófono 'estático', que significa static" (nota 60). As notas de Ana Cristina Cesar têm um funcionamento no mínimo duplo: ora explicam passagens problemáticas e justificam escolhas, ora explicitam o impossível da tradução, seus pontos cegos. Em ambos os casos, colocam na boca de cena os bastidores do processo tradutório e o monólogo hesitante do tradutor. Suas notas não comentam o "original", mas o processo tradutório. São um tipo bastante singular de nota de tradutor, mas continuam sendo notas de tradução. São uma estratégia de tradução que até certo ponto explicita certos dilemas do processo tradutório, mas essas notas não pretendem ser por si mesmas uma tradução: o original e sua tradução continuam em seus respectivos lugares previamente estabelecidos.

Berman, por sua vez, está mais preocupado com a proximidade entre o comentário e a tradução, o comentário como possibilidade de tradução, mostrando como "todo comentário de um texto estrangeiro comporta um trabalho de tradução. No limite, é tradução" 12 (BERMAN, 1999, p. 18, tradução minha).

Atento ao uso singular que pode ser feito do recurso das notas, Berman (1999) menciona uma tradução feita por Proust:

[...] um belo exemplo de tradução e de comentário entrelaçados nos é dado pela versão que Proust fez de Ruskin, em que o texto traduzido se acompanha, página após página, de observações de todos os tipos. Esse trabalho de Proust (aliás um dos mais subjetivos) nos faz lembrar de algo que já havíamos quase esquecido ${ }^{13}$. (p. 18, tradução minha)

12 "Tout commentaire d'un texte étranger comporte un travail de traduction. À la limite, est traduction"

13 "Un bel exemple de traduction et de commentaire entrelaces nous est donné par la version que Proust a faite de Ruskin, où le texte traduit s'accompagne, page après page, de remarques de toutes sortes. Ce travail de Proust (par ailleurs des plus subjectifs) nous rappelle quelque chose que nous avons presque oublié."

Cad. Trad., Florianópolis, v. 38, $\mathbf{n}^{0}$ esp. Baudelaire 150 anos, p. 135-156, ago-dez, 2018 
Esse "algo" quase esquecido diz respeito às possibilidades radicais que o comentário permite no intervalo original-tradução e na relação de ambos com o leitor. "Trabalhando sobre o original e sua tradução, [o comentário] dá acesso simultaneamente à língua do original [...] e ao próprio trabalho tradutório" (BERMAN, 1999, p. 19). Nesse momento, o comentário se torna comentário do original e análise do processo tradutório, insere na tradução uma dimensão do seu processo, da sua atividade.

As semelhanças entre o comentário (tal como pensado por Berman) e as notas de tradução (tal como mobilizadas por Ana Cristina Cesar e por Proust) provavelmente param por aqui. Isso porque, como já mencionei, Berman está tratando de um tipo específico de comentário: o comentário do texto estrangeiro como forma possível de tradução desse texto. Ainda que faça referências às notas de Proust, não se debruça sobre a nota de tradutor, mas sobre a potência do comentário ensaístico como tradução.

Berman formula essas reflexões no livro L'âge de la traduction, publicação póstuma que reúne anotações e parágrafos escritos por ele para uma conferência sobre Walter Benjamin e seu $A$ tarefa do tradutor [Die Aufgabe des Übersetzers]. Comentando microscopicamente o texto de Benjamin, Berman constrói ao mesmo tempo reflexões sobre o ato que empreende, os pontos de contato entre o comentário e a tradução, a relação entre comentar e traduzir. L'âge de la traduction já é ele mesmo uma tradução de $A$ tarefa do tradutor. É uma reflexão e um exemplo sobre como traduzir no nível "energético", como traduzir uma rítmica profunda, traduzir a Letra. Comentário que percorre o texto linha a linha, ainda que não linearmente, traduzindo-o no movimento duplo e oscilante de comentário e tradução. Para evitar apropriações afervoradas, Berman traça uma diferença, e na verdade apenas uma, entre a análise crítica genérica e o comentário. A primeira toma o texto na sua totalidade. Pode destacar essa ou aquela citação, mas sua abordagem é macroscópica. O comentário, por outro lado, percorre o texto micrologicamente. Sem exigência de linearidade, pode ir e voltar, mas se ocupa do texto propriamente dito e traça sobre ele as suas

Cad. Trad., Florianópolis, v. 38, n $^{0}$ esp. Baudelaire 150 anos, p. 135-156, ago-dez, 2018 
linhas de força. É ele seu mapa, dentro do qual serão retraçados certos caminhos e certas fronteiras.

\section{3.}

Até aqui já reunimos as condições necessárias para especificar de que tipo de relação comentário-tradução estamos falando: aquela em que, via comentário, se percorre o texto num gesto crítico da letra do original e se produz, assim, sua tradução.

Ainda que Ana Cristina Cesar atribua um espaço privilegiado para suas notas, guardando uma relação bastante estreita com o comentário tal qual aqui expus, operam como notas de tradução, não pretendem ser por si só um modo de tradução, mas um espaço que, acompanhando o original e sua tradução, veicula a voz, as escolhas e as do "eu" tradutor. A nota do tradutor se constrói a partir do texto traduzido e a ele pontualmente se liga através da distribuição de marcas gráficas. É verdade que, assim fazendo, o texto tem sua unidade e acabamento questionados; afinal, "a nota desfaz a unidade do texto e, assim, destaca o impensado da tradução, seu caráter imperfeito e por ser sempre refeito" 14 (SARDIN, 2007, p. 8, tradução minha). No entanto, o texto traduzido ainda é linearmente idêntico ao original, e é dessa linearidade que se projetam as notas.

No meu caso, interessava-me chegar a uma estratégia de reescrita que me permitisse remontar o texto dentro de uma justa tensão: de um lado, a necessidade de reordenar Mon cœur mis à nu fora da ordenação canônica de Poulet-Malassis (a falta de uma ordenação prévia é, afinal, um dos inacabamentos constitutivos dessa escrita); de outro, buscar (ou melhor, construir) linhas de força em Mon cœur mis à nu que me permitissem não recorrer nem a procedimentos redutores (papéis avulsos, arranjo randômico virtual etc.) nem a uma tentativa (inviável) de reconstituir uma suposta

\footnotetext{
14 "la note défait l'unité du texte et, ce faisant, alerte sur l'impensé de la traduction, son caractère imparfait et toujours à re-faire."
}

Cad. Trad., Florianópolis, v. 38, $\mathbf{n}^{0}$ esp. Baudelaire 150 anos, p. 135-156, ago-dez, 2018 
genealogia do manuscrito. Essas linhas de força são as tensões, oscilações e repetições que, produzindo aproximações e diferenças, rearranjam o texto segundo outros percursos possíveis. Para mim, a questão do inacabamento da ordenação não diz respeito a não haver "ordenação nenhuma", o que levaria às soluções redutoras que mencionei, mas a não ser possível uma ordenação definitiva, o que pede da parte do editor-tradutor uma relação radicalmente crítica com o material.

O ensaio funciona, assim, como estratégia de tradução. O comentário ensaístico é ele mesmo tradução. Se as notas de tradutor ao estilo das produzidas por Ana Cristina César e Proust são uma estratégia que explicita os nós do processo tradutório, o comentário-ensaio como tradução é ele mesmo processual, um caminhar sobre o original que vai redesenhando antigos trajetos, religando novos caminhos. Diz Berman (1999): “[o] comentário é uma experiência feliz na qual avançamos sem saber o que vai surgir daí" 15 (p. 66-67, tradução minha). Ao ter um olhar microscópico sobre o texto, permite a identificação de certos pontos sísmicos que montam o texto a partir de outras tectônicas.

Ao me debruçar sobre os manuscrito ${ }^{16}$ encadernados por Poulet-Malassis, disponíveis na Gallica, percebi dois dados relevantes na sua ordenação: 1) não se trata de uma ordenação temática; certos temas vão e voltam ao longo de todo o texto; por exemplo: o tema do "dândi" aparece nas notas 5, 16, 22, 33 e 59 (numeração de Malassis); 2) a ordenação de Malassis tem no mínimo dois "furos" - as notas 28 e 28 bis e as notas 45,45 bis (I) e 45 ter (II) ${ }^{17}$

15 "Le commentaire est une expérience heureuse dans laquelle on avance sans savoir ce qui va advenir"

${ }^{16}$ Baudelaire, 1801-1900. Para seguir a explicação da nota seguinte, é fundamental acessar o fac-símile dos manuscritos (Cf. lista de referências).

17 - 28 e 28 bis: Pichois (2001, p. 13) explica que a inscrição 28 bis não foi feita por Malassis, mas por Eugène Crépet (editor, relembremos, da primeira edição parcialmente integral). A disposição das duas notas nas folhas de grande formato também é singular. O fragmento 28 bis está por baixo do 28 , que está preso apenas pela ponta superior esquerda. Assim, pode ser levantado, permitindo ler o 28

Cad. Trad., Florianópolis, v. 38, $\mathrm{n}^{0}$ esp. Baudelaire 150 anos, p. 135-156, ago-dez, 2018 
- que desnaturalizam a sua ordenação e fazem surgir por dentro dos manuscritos assim ordenados a verdade da sua desordem e a possibilidade da sua reordenação.

Se por um lado a arbitrariedade da ordenação canônica de Malassis me parecia um aspecto importante dos inacabamentos de Mon cœur mis à $n u$, por outro não encontrava a estratégia que me permitisse trabalhar sobre sua ordenação sem cair nas soluções redutoras ou "genealógicas". Levando em conta que já tinha uma tradução feita (a tradução "diplomática", "manuscrítica”, ou como

bis. Como a colagem dos fragmentos e a encadernação dos manuscritos é obra de Malassis, fico tentado a afirmar que essa disposição é de sua autoria. Crépet teria tão somente dado uma numeração "suplementar" (28 bis) a um fragmento que já estava onde estava, mas sem numeração. Outra pergunta: de que modo esses dois fragmentos ( 28 e 28 bis) se encontravam nos manuscritos para que Malassis os colasse juntos, estabelecendo entre eles uma relação que, apesar de não estar dita, remete a certa identidade? $\bullet 45,45$ bis (I) e 45 ter (II): trata-se de um caso ainda mais singular, e que novamente explicita a intervenção (limitada, é verdade) de Eugène Crépet nos manuscritos após o trabalho de Malassis. Para começar, a folha de grande formato está numerada como 55, contendo, por sua vez, as notas 45 bis (I) e 45 ter (II), esta tendo ainda o título "Prière". A nota 45, que não apresenta nada de especial, está na folha de grande formato de número 25 . A folha 26 contém as notas 46 e 47.45 bis (I) e 45 ter (II), colados na folha 55 , promovem, assim, uma descontinuidade imediata na suposta estabilidade de ordenação canônica. Detalhe relevante: a nota 45 ter (II), "Prière", está colada sobre a nota 45 bis (I). E a nota 45 bis (I), por sua vez, colada sobre a folha de grande formato 55. A denominação 45 bis (I) e 45 ter (II) deve ser melhor explicada: " 45 bis" e "45 ter" são indicações escritas a lápis, ao lado das notas, sobre a folha de grande formato. Os algarismos "I" e "II" estão escritos diretamente sobre o papel de cada uma das notas. Na reprodução digital dos manuscritos (Gallica.fr), a folha 55 aparece como "non paginé", e disposta antes da própria abertura de Mon coeur mis à nu. Na edição de André Guyaux (2011), temos as indicações 45 bis e 45 ter, dispostos entre as notas 45 e 46. Nas Oeuvres complètes da Pléiade (1983), organizadas por Pichois, não temos nem bis nem ter, mas "non numéroté", e também entre as notas 45 e 46. Na edição diplomática de Pichois (2001), aparecem as inscrições “[non numéroté] I [45 bis]” e “[non numéroté] II [45 ter]”, sequenciados entre 45 e 46. O mais importante está no seu prefácio: Pichois (2001, p. 14) explica que foi Eugène Crépet quem assim colocou essas duas notas que Malassis não numerara. Assim, juntou sequencialmente 45 e 45 bis, unidos pelo tema da prostituição, e seguidos da "Prière" (45 ter).

Cad. Trad., Florianópolis, v. 38, n $^{0}$ esp. Baudelaire 150 anos, p. 135-156, ago-dez, 2018 
pudermos vir a nomear), e que ao mesmo tempo iam se acumulando anotações, planos de parágrafos, citações de leituras críticas etc. sobre Mon cœur mis à nu, comecei a me dedicar ao coração ensaístico da tese. E percebi, a seguir, que meu processo de escrita havia me levado a recortar as notas de Mon cour mis à nu, espalhando-as sobre a mesa e traçando itinerários, agrupamentos e cisões conforme certas linhas de força guiavam o ensaio (e, na verdade, meu modo de ler e construir o "original”). A essa práxis se juntou a episteme bermaniana, e então se tornou mais claro que, ao escrever sobre Mon cœur mis à nu recortando, desarranjando e rearmando as notas da ordenação canônica, eu já estava produzindo a segunda reescrita do projeto, aquela que trataria da movência sequencial das notas. Para evitar certos excessos e ressaltar a relação entre comentário e tradução, estilhacei as notas pelas margens do ensaio, conforme as linhas de força se desenhavam, davam e se davam a ler.

Dois exemplos, um que diz respeito a uma linha de força "estrutural" e outro a uma linha de força "temática":

1) Ao expor os furos na ordenação de Malassis - notas 28 e 28 bis e 45, 45 bis (I) e 45 ter (II) -, essas notas espalham-se pelas margens do ensaio e são lidas conjuntamente (reparem que, na ordenação canônica, estão consideravelmente distantes): 
Figura 1 - "Flânerie guiada a Mon cœur mis à nu" (trecho), capítulo da tese $O$ rascunho contínuo: duas retraduções de Mon cœur mis à nu, de Charles Baudelaire

- 45, 45 bis (I) e 45 ter (II): trata-se de um caso ainda mais singular, e que novamente explicita a intervenção (limitada, é verdade) de Eugène Crépet nos manuscritos após o trabalho de Malassis. Para começar, a folha de grande formato está numerada como 55, contendo, por sua vez, as notas 45 bis (I) e 45 ter (II), esta contando ainda com o título "Prière". A nota 45, que não apresenta nada de especial, está na folha de grande formato de número 25 . A folha 26 contém as notas 46 e 47.45 bis (I) e 45 ter (II), colados na folha 55, promovem, assim, uma descontinuidade imediata na suposta estabilidade de ordenação canônica. Detalhe relevante: a nota 45 ter (II), "Prière", está na verdade colada sobre a nota 45 bis (I), que tem um papel maior. E a nota 45 bis (I), por sua vez, colada sobre a folha de grande formato 55 . Além disso, a denominação 45 bis (I) e 45 ter (II) deve ser melhor explicada: " 45 bis" e " 45 ter" são indicações escritas a lápis, ao lado das notas, sobre a folha de grande formato. Os algarismos "I" e "II" estão escritos diretamente sobre o papel de cada uma das notas. Na reprodução digital dos manuscritos (site da Gallica.fr), a folha 55 aparece como "non paginé", e disposta antes da própria abertura de $M e u$ coração nu e cru. Na edição de André Guyaux (1986), temos as indicações 45 bis e 45 ter, dispostos entre as notas 45 e 46 . Nas Oeuvres complètes da Pléiade (1975), organizadas por Pichois, não temos nem bis nem ter, mas "non numéroté", e também entre as notas 45 e 46 . Na tradução de Aurélio (1981), todas as numerações são alteradas: 45 bis vira 46 , e assim por diante. Na de Guerreiro (1995), aparece a inscrição "não numerada", vindo entre 45 e 46. Na de Tadeu (2009), temos 45a e 45b. Na de Tenfen (2013), já que ele não

o que é o amor? A necessidade de sair de si. O homem é um animal adorador. adorar é se sacrificar e se prostituir.

Então todo amor é prostituição.

O ser mais prostituído é o ser por excelência, é Deus, porque é o amigo supremo de cada indivíduo, porque é o reservatório comum, inesgotável do amor.

Prece

Não me castigueis em minha mãe, e nem castigueis minha mãe por minha causa. Aconselho-vos as almas do meu pai $\mathrm{e}$ de Mariette. - Daime a força para

Fonte: Mattos, 2018, p. 380.

2) Ao falar da "escrita de cólera" em Mon cœur mis à nu, refiro-me especialmente a algumas notas de conteúdo, digamos, realmente encolerizado: são trechos contra a França, contra as mulheres, contra os judeus, contra a cultura literária francesa. Essas notas, que na ordenação canônica estavam espalhadas, agrupam-se numa espécie de núcleo explosivo de Mon cœur mis à nu, livro, dizia Baudelaire $\left(1973\right.$, p. 141) em carta para a mãe ( $1^{\circ}$ de abril de 1861), "onde colocarei todas as minhas cóleras". 
Figura 2 - "Flânerie guiada a Mon cœur mis à nu" (trecho), capítulo da tese $O$ rascunho contínuo: duas retraduções de Mon cœur mis à nu, de Charles Baudelaire

Parte da crítica chegou a notar essa relação entre Meu coração nu e cru e a cólera, a impertinência, a irritação: "Baudelaire tomou suas notas ao sabor da sua inspiração ou da sua irritação" 36 (PICHOIS, 2001, p. 10).

De volta à sua correspondência pessoal, são numerosas as passagens em que Baudelaire revela, mesmo sem situar o assunto no plano de Meu coração nue cru, sua aproximação com uma escrita de cólera, a escrita que, como uma bomba, pode atingir um país: "Tenho horror à vida. Repito: - quero fugir da face humana, mas sobretudo da face francesa"37 (BAUDELAIRE, 1973, p. 254); "quero colocar toda a raça humana contra mim"38 (BAUDELAIRE, 1973, p. 553); "nesse livro atroz [Les fleurs du mal], coloquei todo meu coração, toda minha ternura, toda minha religião (travestida), todo meu ódio"39 (BAUDELAIRE, 1973, p. 605).

Fusées também oferece um trecho revelador: "Quando eu tiver inspirado o desgosto e o horror universais, terei conquistado a solidão. [...] 0 que tem de inebriante no mau gosto é o prazer aristocrático de desagradar"40 (BAUDELAIRE, 1975, p. 660-661).

Parte da crítica baudelairiana atribui à questão da cólera, aliás, um traço diferenciador possível entre os projetos Meu coração nu e cru, Fusées e Hygiène. Outra distinção possível é de caráter mais formal. Tentarei explicar. É o penúltimo assunto (o último é a questão da ordenação de Malassis em detalhes) de que preciso tratar antes de abandonar esta investida factual.

Entedio-me na França, sobretudo porque todo mundo aqui se parece com Voltaire.

Voltaire, como todos os preguiçosos, odiava o mistério.

Da necessidade de bater nas mulheres. Pode-se castigar o que se ama. Assim as crianças. Mas isso implica a dor de desprezar o que se ama.

Da Cornice e dos Cornos

A Dor do Corno. Ela nasce do seu orgulho, de um raciocínio falso sobre a honra e a felicidade, e de um

Fonte: Mattos, 2018, p. 406.

Como se vê, o comentário como tradução do original permite iluminar um aspecto preciso dos inacabamentos de Mon cœur mis à nu: não se trata mais do inacabado como manuscrito isolado, ou melhor, a página como unidade de inacabamento; trata-se aqui da própria ordenação e arranjo da obra como um rascunho, como inacabamento móvel. 


\section{4.}

Para terminar, vejamos brevemente de que maneira esse tipo de reescrita que proponho se situa em relação aos fazeres tradutórios de Ana Cristina Cesar e Antoine Berman.

Os tipos de comentários feitos por Berman e Ana Cristina Cesar não se pretendem "desbravadores" de sentidos ocultos do texto. Há algum nível de análise crítica, o que é inevitável e necessário, mas o que esse tipo de comentário traz de mais produtivo é o estabelecimento de um outro tipo de relação com o "original" e sua tradução. Ambos deixam de ser objetos estáveis e passam a ser uma atividade de leitura, interpretação e reescrita. Não são comentários que "solucionam" impasses, mas inserem o leitor nessas hesitações, fazem com que ele se mova no e com o processual. É claro que não se deve aproximar tão diretamente o que fez Berman em L'âge de la traduction e o que fez Ana Cristina Cesar com "Bliss". Há diferenças. A começar pelo perfil de tradutor e autor de cada um, passando pelo tipo de texto com que trabalham e o tipo de relação que estabelecem com o "original". Berman, por exemplo, transforma o ensaio em um comentário-tradução; Ana Cristina Cesar permanece numa tradução "propriamente dita", recorrendo às notas de tradutor para construir uma relação mais movediça e menos cabal com as soluções tradutórias. Em Ana Cristina César, a nota-comentário é uma estratégia de tradução para colocar em cena o processo de tradução. Em Berman, o ensaio-comentário é ele mesmo o processo de tradução, um método tradutório que não se sustenta pela sistematização organizada, mas pela experimentação processual, ou pelo processo experimental. As "leis" do comentário se formam no fazer tradutório. O próprio Berman (1999, p. 94) chega a afirmar que "a crítica é sempre uma certa experimentação a partir de uma obra”. Nesse caso, acrescentemos, dupla experimentação: a experimentação da crítica ensaística e da tradução como crítica.

O recurso do comentário, seja pela nota de tradutor, seja pelo comentário como tradução, também abre o texto para além da sua sequência pré-definida, seja ela qual for. Para não sair do que já nos é familiar, tomemos o exemplo de Ana Cristina Cesar. Trata-

Cad. Trad., Florianópolis, v. 38, n $^{0}$ esp. Baudelaire 150 anos, p. 135-156, ago-dez, 2018 
-se de um conto publicado pela sua própria autora. Não há qualquer questionamento sobre a ordenação daquele texto. Ainda assim, os comentários inseridos por Ana Cristina Cesar ao longo do texto acrescentam "rasgos" na malha do texto. Se o leitor resolver parar a leitura num desses pontos e ler a nota, para só depois voltar, fará um tipo de leitura que já não é perfeitamente obediente à sua linearidade constitutiva. Essa relativa "desordem" foi construída pela tradutora, não estava dada, o que prova que, até na ordenação de um texto "acabado", "as notas nos lembram de que a tradução é um jogo de escrita(s) com regras nunca estabelecidas, sempre negociáveis" ${ }^{18}$ (SARDIN, 2007, p. 1, tradução minha).

Do mesmo modo, ainda que muito diferentemente, Berman quebra a suposta linearidade de $A$ tarefa do tradutor. Não o percorre linearmente, mesmo havendo uma linearidade geral que guie sua leitura. Por isso mesmo, se um leitor mais atento quiser ler seus comentários acompanhando o texto, necessariamente fará uma leitura que não seguirá a ordenação pré-definida. Novamente, o comentário produz rasgos e dobras nesse tecido, possibilitando outros encaixes e relações, outras entradas e outras saídas.

No meu caso, o ensaio como tradução do original configura-se como uma estratégia de reescrita que permite rearmar o original a partir de outros pressupostos: diferentes linhas de força que, organizando o ensaio, reorganizam o original, fazendo-o operar segundo uma ordenação só possível pela relação estabelecida entre o ensaio e o texto em questão.

Assim, o lugar do comentário na tradução não é só o da nota, do prefácio e do posfácio. É também o lugar do ensaio ${ }^{19}$, do ensaio como tradução.

18 "les notes nous rappellent que la traduction est un jeu d'écriture(s) aux règles jamais établies, toujours à négocier."

${ }^{19}$ Há uma bibliografia mais ou menos vasta e "canonizada" sobre o ensaio: Lukács, Adorno, Berardinelli... Ainda poderíamos citar, transversalmente, as experiências de Édouard Glissant, Octavio Paz, Simone Weil... Há, claro, muitas nuances. Não é meu objetivo entrar em considerações sobre as singularidades do gênero ensaístico. Limito-me, pelo menos neste ensaio, ao uso que se pode fazer do ensaio como estratégia e experimentação de tradução.

Cad. Trad., Florianópolis, v. 38, $\mathrm{n}^{0}$ esp. Baudelaire 150 anos, p. 135-156, ago-dez, 2018 
Ao invés de estabilizar o texto, pode-se percorrê-lo via comentário, processualmente. As linhas de força explodem a ordenação de Malassis e promovem outras armações possíveis, construídas tendo por base um ensaio que percorre Mon cœur mis à nu não linearmente, a partir de certas tendências, sismos, forças e gravidades. É um equilíbrio entre a dispersão da reordenação e a concentração da crítica, potência da forma ensaística.

\section{Referencias}

BAUDELAIRE, Charles. Euvres complètes. Paris: Gallimard, 1983.

. Correspondance II. Paris: Gallimard, 1973.

. Mon cour mis à nu. Édition diplomatique établie par Claude Pichois. Genève: Librairie Droz, 2001.

. Mon cœur mis à nu. Hygiène - Manuscrit autographe [1801-1900]. Bibliothèque Nationale de France. Disponível em: < https:/gallica.bnf.fr/ark:/12148/ btv1b84516210.image > . Acesso em: 5 set. 2017. (Manuscrito autógrafo)

BENHAMOU, Françoise. Le livre à l'heure numérique. Paris: Seuil, 2014.

BERMAN, Antoine. L'âge de la traduction. Paris: PUV, 1999.

BLIN, Georges; CRÉPET, Jacques. Introduction: notes, éclaircissements et commentaires critiques. BAUDELAIRE, Charles. Journaux intimes: Fusées, Mon cœur mis à nu, Carnet. Paris: José Corti, 1949. [s. p.]

CESAR, Ana Cristina. O conto Bliss anotado. . Crítica e tradução. São Paulo: IMS ; Editora Ática, 1999. p. 281-355. 
CRÉPET, Eugène. Journaux intimes : Fusées ; Mon cœur mis à nu. BAUDELAIRE, Charles. Euvres posthumes. Paris: Maison Quantin, 1887. p. 67-70.

FALEIROS, Álvaro; MATTOS, Thiago. A retradução de poetas franceses no Brasil: de Lamartine a Prévert. São Paulo: Copetti Editor, 2017.

GALÍNDEZ, Verónica. Descontinuidade e leitura de manuscritos. Revista Manuscrítica, São Paulo, n. 16, p. 10-24, 2009.

GIMÉNEZ, Diego. El nuevo Livro do desassossego de Jerónimo Pizarro. MatLit, v. 1, n. 2, p. 165-171, 2013.

GUYAUX, André. Préface. BAUDELAIRE, Charles. Fusées. Meu coração nu e cru. La Belgique Déshabillée. Paris: Gallimard, 2011 [1986].

KOMESU, Fabiana. Pensar em hipertexto. ARAÚJO, J. C.; BIASI-RODRIGUES, B. (Orgs.) Interação na internet: novas formas de usar a linguagem. Rio de Janeiro: Lucerna, 2005. p. 87-108.

MATTOS, Thiago. (Re)traduções brasileiras de Mon coeur mis à nu, de Charles Baudelaire. 2015. Dissertação (Mestrado em Letras) - Universidade de São Paulo, São Paulo.

. O rascunho contínuo: duas retraduções de Mon cœur mis à nu, de Charles Baudelaire. 2018. Tese (Doutorado em Letras) - Universidade de São Paulo, São Paulo.

PICHOIS, Claude. Notice. BAUDELAIRE, Charles. Euvres complètes. Paris: Gallimard, 1983.

. Introduction. BAUDELAIRE, Charles. Mon cœur mis à nu. Édition diplomatique établie par Claude Pichois. Genève: Librairie Droz, 2001.

POE, Edgar A. Contes, essais, poèmes. Tradução de Jean-Marie Maguin e Claude Richard. Paris: Robert Laffont, 1995. (Coll. Bouquins) 
PORTELA, Manuel. Nenhum Problema Tem Solução: Um Arquivo Digital do Livro do Desassossego. MatLit: Materialidades da Literatura, v. 1, n. 1. Coimbra, p. 9-33, 2013.

POSSENTI, Sírio. Notas um pouco céticas sobre hipertexto e construção de sentido. __ Os limites do discurso: ensaios sobre discurso e sujeito. Curitiba: Criar, 2002. p. 205-225.

RIGEADE, Anne-Laure. Vers une pensée du texte traduit: une lecture de Pnine et Feu pâle et d'un extrait des deux traductions françaises de Ulysses. Palimpsestes, n. 20. Paris, p. 177-200, 2007.

SARDIN, Pascale. De la note du traducteur comme commentaire: entre texte, paratexte et pretexte. Palimpsestes, n. 20. Paris, p. 121-136, 2007.

Recebido em: 27/09/2018

Aceito em: 12/10/2018

Publicado em dezembro de 2018

Thiago Mattos de Oliveira. E-mail: thiagomattos.lit@gmail.com ORCID: https://orcid.org/0000-0003-2689-6127 